\title{
Comedias y tragedias
}

Cervantes, Miguel de

Ed. al cuidado de Luis Gómez Canseco, Madrid,

Real Academia Española, 2016.

No fueron pocos - si bien tampoco exclusivos - los esfuerzos de Cervantes por abrirse campo y conseguir reconocimiento en un ámbito que sin duda le apasionó. El teatro para Cervantes trasciende los límites de lo genérico, constituyendo un elemento central, tanto temático como estructural en toda su producción literaria; prueba de ello la cantidad de alusiones, referencias, debates y situaciones teatrales en sus obras narrativas. Del mismo modo, sus piezas dramáticas no quedan al margen de sus intereses y reflexiones de naturaleza (meta) literaria. En ellas hará gala de una gran libertad y consciencia poética, llevadas a sus últimas consecuencias en muchas ocasiones. No obstante, sus propuestas no fueron entendidas o tal vez no pudieron competir con el nuevo arte de la triunfante fórmula lopesca. Estas inoportunas coordenadas parecen haber permeado el tiempo, pues la sombra del monstruo de la naturaleza ha seguido sesgando la mirada de los críticos hacia las obras dramáticas del alcalaíno, siendo especialmente desfavorecidas las comedias que pasaron a la estampa en vida del autor. Frente a esta tradición crítica, es sin duda valioso y encomiable el trabajo del equipo de Gómez Canseco para recuperar la unicidad de estas propuestas dramáticas, que solo se pueden entender en sí mismas y desde su contexto.

Se reúnen en Comedias y tragedias las once piezas largas que se conservan de la producción teatral cervantina: aquellas publicadas en las Ocho comedias y ocho entremeses nuevos nunca representados (1615), más tres de la primera etapa, cuyos textos no están recogidos en las Ocho y cuya transmisión manuscrita es la única que los atestigua. Cabe destacar la inclusión en esta colección de La conquista de Jerusalén por Godofre Bullón, añadida solo recientemente al canon de la producción dramática cervantina y publicada aquí por primera vez integrando el corpus. El texto crítico de las obras se presenta de for- 
ma cabal en el primer volumen del libro, con sucintas pero relevantes notas a pie de página y precedido únicamente por un breve prólogo que introduce con claves interpretativas básicas el teatro de este escritor, a saber, la libertad poética que informa sus propuestas, el tipo de coherencia temática y estructural que pone en práctica, o el relevante papel de la dimensión espectacular en sus obras. Por su parte, para el segundo volumen -complementario- se reservan los estudios, los aparatos críticos, los apéndices y la bibliografía. La doble transmisión textual por la que nos han llegado los textos cervantinos - y que estudia pormenorizadamente Presotto en el espacio dedicado a la "Historia del texto" - aporta datos de la relación del escritor con el mundo de la farándula. Si la tradición textual del libro impreso es indicativa de su éxito escaso, las piezas manuscritas parecen confirmar las palabras de Cervantes en su prólogo a las Ocho acerca de una primera etapa algo más célebre. Esta queda avalada, además, por toda una serie de pruebas documentales que Pinzan y Colombo se encargan de recoger y desarrollar en el "Anejo III".

Como estudian Gómez Canseco y Ojeda Calvo en el capítulo que abre el estudio, una de las claves de contextualización de la obra dramática del autor del Quijote se desprende de su vínculo con el teatro propio del último tercio del Quinientos, que recoge influencia popular, humanista e italiana. Estas tendencias marcan los intereses de toda una generación transicional en la que Cervantes se inserta y desde la cual se inicia en la dramaturgia, tratando de aportar su particular visión y perspectiva. Esta formación incide de modo más directo en sus primeras obras, y valida las convicciones que refleja su producción posterior, explicitadas en el ya mencionado prólogo. Aparte de las ideas estéticas y morales que inspiran sus propuestas, otras circunstancias más terrenales y profanas influyen en su trayectoria. Esta viene marcada, como prueban los dos estudiosos, por una tensión dialéctica entre sus propias ideas literarias y la necesidad de llegar al público y ganarse el pan, lo que genera una dinámica de reevaluación y reivindicación constante, tanto de sus propuestas estéticas e ideológicas como de su calidad como dramaturgo. De este modo, el minucioso trabajo de reconstrucción biográfico-literaria que llevan a cabo Gómez Canseco y Ojeda Calvo no solo es pertinente, sino sumamente relevante para entender la obra dramática de Cervantes. A estas coorde- 
nadas contextuales añaden los críticos las claves infraestructurales de la evolución del negocio de la farándula, la estabilización y profesionalización de sus medios y agentes, y cómo este proceso generó unos canales restringidos y dependientes de la demanda en el círculo comercial, en donde solo unos pocos dieron con la receta del éxito.

No encontró cabida en tanta estrechez la libertad poética del autor del Quijote. Sus propuestas temáticas, estructurales, estéticas y escenográficas son ejes y cauces de reflexión literaria, más allá de toda convención. Los editores hacen un excelente trabajo al destacar la mirada paródica y subversiva en las comedias cervantinas, que - como recuerda García Aguilar- no tratan de imponer meramente una ruptura, sino que invitan a la revisión de los modelos vigentes, muy en la tónica cervantina. Es así cómo se entiende la peculiar construcción de las intrigas, o los poco decorosos personajes que las pueblan, proyectados tanto unas como otros más allá de las fronteras diegéticas. La misma noción de teatro y teatralidad, explotada por diversos flancos en las obras, se problematiza. Y es que Cervantes experimenta con todos los recursos a su alcance, desde las posibilidades técnicas que los corrales ofrecen hasta la materia disponible para su dramatización, siempre explorando los límites de la espectacularidad, por un lado, y los de la ficción, la realidad y la verosimilitud, por otro.

La extrañeza o desconcierto que causó y que ha seguido inspirando en la crítica el teatro cervantino, acusado de inconsistencia y falta de unidad, tal vez se deba en parte a una mala comprensión de sus planteamientos dramáticos y escénicos, que buscan mover a la admiratio, tanto visual como conceptual. Como apunta Rico García, "no [sería] lógico pensar que quien había reprobado insistentemente los disparates que producía la falta de verosimilitud argumental, pusiera en letra de molde y ofreciera - con sello de garantía de sus convicciones teóricas sobre la literatura en general y sobre la comedia en particular - incongruencias formales, inconsistencias en la estructura y escasa credibilidad en el comportamiento de los personajes" (p. 134).

Otro de los objetivos que se marcan los editores de las Comedias $y$ tragedias es volver sobre la cuestión de la datación de las obras. Este tema, tratado ya por la crítica, aquí se aborda de forma exhaustiva, teniendo en cuenta y cotejando cronología externa 
-datos materiales, documentales y biográficos - e interna — datos textuales y eruditos-. Ambas, que se recogen de forma detallada y por extenso en el estudio particular que cada editor realiza sobre su obra en cuestión, los reúnen Canseco y Ojeda con perspectiva global, proponiendo una hipótesis de reconstrucción cronológica del itinerario compositivo dramático de Cervantes. Este trabajo, lejos de pretender la dilucidación sin más del dato, se plantea como un adentramiento en el taller literario cervantino, en el que se advierte una práctica de constante reescritura y de reaprovechamiento de materiales, que incide en esta doble dinámica de revalidación y reivindicación de su obra, por un lado, y que, por otro, nos aporta una imagen más cabal del autor del Quijote.

Todo esto y más revela el cuidadoso estudio de las Comedias y tragedias que este equipo procura. En ellas se despliega un amplio catálogo de posibilidades dramáticas, no reductibles a ninguna fórmula o patrón. Debida cuenta dan de ello los editores en "Lecturas cervantinas", constatando cómo se actualiza en cada caso la impronta cervantina. En este espacio, en el mismo orden en el que se presentan los textos editados, cada editor vuelve sobre la cronología, la contextualización —biográfica, literaria e histórica-, y profundiza en fuentes, materiales y construcción dramática, cuestiones escenográficas y visuales, así como en peculiaridades de cada pieza. Se excluye de este espacio el resumen pormenorizado de las tramas, quedando estas recogidas en el primer dosier de los apéndices.

Gómez Canseco se encarga de la primera comedia que figura en el impreso, El gallardo español, donde verdad histórica y ficción, actualidad política y ecos caballerescos y moriscos, se funden en una fábula dramática, que halla su eje en un desafío de honor a la antigua usanza. Cervantes recoge puntualmente fechas, nombres y hechos históricos de crónicas y otras fuentes (entre ellas la propia experiencia personal) para dar consistencia a la acción histórico-bélica, cuya compleja trama se conjuga y armoniza en el protagonista. Muy al contrario ocurre en La casa de los celos, que estudia Fernández López. En esta comedia, la cantidad de personajes sobre la escena supone un foco de dispersión. A través de una abrumadora variedad de elementos distribuidos en intrigas yuxtapuestas se enfrentan lo bucólico y lo caballeresco, generando una ficción 
de ficciones tan fantástica como absurda, pero cuyo juego paródico parece ser el eje armonizador de la obra. Con todo, Fernández López desentierra otras posibles claves interpretativas, en virtud de ciertos datos genéricos y contextuales, que añadirían en la comedia una aguda mirada a hechos de actualidad política.

Guiños a circunstancias inusitadamente actuales halla también $\mathrm{Ba}$ ras Escolá en Los baños de Argel, que Cervantes pudiera haber dedicado simbólicamente a los que saldaron la deuda de su redentor. A vueltas con la realidad, esta pieza vuelve a conjugar ficción y verdad histórica, a la que se suma la experiencia personal del cautiverio, eje temático del que se desprenden los conflictos dramáticos de la obra. Un cuidadoso escrutinio de datos y referencias varias llevan a este editor a recontextualizar el momento compositivo de esta obra. Esta no solo bebe de su antecedente El trato de Argel, escrita y representada en la primera etapa, sino que además parece estar en peculiar diálogo (y competición) con la comedia del mismo asunto de Lope, que - como indican Pinzan y Colombo en el tercer anejo- pudo haber aprovechado una propuesta exitosa de Cervantes para reelaborarla a su modo.
Fuentes de otro tipo son las que informan, como advierte Núnez Rivera, El rufián dichoso, donde Cervantes se atreve de forma pionera con materia de santos, si bien aderezándola con un importante componente picaresco. Historia hagiográfica, tradición literaria e imaginación confluyen en un «baciyélmico» protagonista, cuya suerte proteica trasciende con libertad cervantina los lazos de cualquier determinismo, ya estético, ya moral. De nuevo, el reto que tal variedad y contrastes suponen para la construcción dramática y la verosimilitud hallan su camino de forma consistente al margen de consignas clásicas. Cervantes experimenta constantemente con recursos de coherencia y ensamblaje, cuyos resultados — de difícil escenificación- más bien parecen propuestas de lectura que para las tablas, lo que suscriben también Fernández López y Baras Escolá con respecto a las dos piezas anteriores. Como apunta Presotto, el inicio de la práctica de la lectura del teatro parece datar de finales del XVI, sancionándose en el XVII con el modelo editorial de las partes de comedias lopescas. Cabe sospechar que Cervantes llegara a pensar alguna de estas comedias en esta clave, lo que aclararía — según 
él mismo apunta en La Adjunta del Parnaso - ambigüedades estructurales y problemas de verosimilitud.

En defensa nuevamente de la unidad y coherencia dramática, Gómez Canseco aborda el estudio de La gran sultana, cuyas intrigas paralelas, tan del gusto cervantino, combinan exotismo turquesco, aventura bizantina y actualidad política. Gómez Canseco rastrea referentes que bien pudieron ser reconocibles, en virtud de los cuales la verosimilitud quedaba garantizada. En esta pieza, cautiverio y libertad, insertos en una trama amorosa, vuelven a ser ejes temáticos y estructurales. Libre e intrincada es asimismo la comedia El laberinto de amor, que lleva a Rico García a considerar la obra como otra propuesta de teatro para la lectura, si bien aquí estima imprescindible la dimensión escenográfica para su cabal entendimiento e interpretación. Y es que, pese a la dificultad que entraña su datación por cuanto que carece de indicios textuales o históricos palmarios, todo apunta a que esta, como La entretenida y Pedro de Urdemalas, fueron escritas tardíamente, cuando ya Cervantes había asumido su fracaso en los círculos de la farándula.

En las tres piezas se advierten elementos dramático-estructurales del
Arte nuevo - ya consolidado por esas fechas- en clave, por supuesto, paródica. García Aguilar explora cómo las convenciones de la comedia de enredo lopesca se subvierten hasta sus últimas consecuencias en La entretenida, donde el matrimonio no es una solución, como venía siéndolo en el teatro de Lope, sino un problema. El afán experimental cervantino se orienta claramente hacia la indagación de límites y posibilidades literarias, jugando hábilmente para ello con todos los resortes dramáticos disponibles. De esta forma, el artificio, la (meta) teatralidad, el engaño y el disfraz adquieren una relevancia particular, que rompen con toda expectativa. En la misma línea anda Pedro de Urdemalas, guinda de las Ocho comedias de Cervantes o, como la define Sáez, "su jugada más arriesgada y original, que además tiene sabor a despedida del teatro". Esta obra funde tradición literaria y popular por medio del folclore, lo festivo y la picaresca. De nuevo, se advierte un alarde de libertad, tanto moral como estética, que invita a reflexionar sobre la naturaleza humana y la ilusoria teatral.

Algo distintas son las obras que siguen, las pertenecientes a la tradición manuscrita. En lo que respecta a El trato de Argel, Ojeda Calvo 
señala el reajuste de cuatro a tres jornadas y el uso de las figuras morales como portavoces de conflictos interiores, entre otros rasgos. De nuevo, la libertad goza de particular relevancia, aquí matizada con una actitud fuertemente estoica. Pese a las recientes interpretaciones sobre tolerancia y pacifismo que la crítica ha detectado en esta y otras comedias, Ojeda llama la atención sobre la importante presencia de ideología españolista y cristiana, observación que previamente apoya Gómez Canseco con respecto a Los baños o La gran sultana. Un acercamiento en similar clave interpretativa es el que desarrolla $\mathrm{Ba}$ ras Escolá en la famosa Tragedia de Numancia. Baras rastrea las fuentes literarias e históricas, inserta la obra en la tradición senequista y despliega las claves de actualización de la obra en las coordenadas coetáneas a la realidad del escritor, que alinearían el ejemplo numantino con la realidad conflictiva imperial de Felipe II. Por último, Antonucci confirma la autoría cervantina para La conquista de Jerusalén por Godofre de Bullón, desvelando vínculos con el resto de la producción cervantina. Esta obra, en semejanza estructural con la Numancia, combina historia y épica en su ficción, con importantes dosis, de nuevo, propagandísticas. Es esta una obra con visos de culta, dirigida a un público entendido en materia épica y de gusto retórico más refinado. Como apunta Presotto en la "Historia del texto", estas tres obras constituyen una significativa y valiosa muestra de la fase experimental del teatro peninsular, a la que Cervantes efectivamente contribuyó y de la que queda tan poca noticia. La tradición manuscrita de estas obras cervantinas, por tanto, presenta interés en gran parte por su valor documental, aparte del literario. Los testimonios existentes presentan un alto grado de corrupción y textos significativamente distintos en ocasiones, lo que supone todo un desafío para la labor del editor. Presotto describe de forma exhaustiva los manuscritos para cada una de las obras, cotejándolos, comentando sus características, los puntos de confluencia y divergencia, tipo de intervenciones y errores, aportando pistas de filiación, de procedencia, y, en definitiva, claves interpretativas para reconstruir el momento de transmisión en que cada uno de estos eslabones se inserta. Este panorama lo completa el trabajo de Vaccari, recogido en el cuarto apéndice, en el que examina pormenorizadamente los papeles de actor y estudia el problemático 
parentesco con los manuscritos. En el caso del Trato de Argel se puede vislumbrar con más claridad la filiación con uno de ellos. La Conquista de Jerusalén representa un caso de estudio complejo, pues las divergencias entre los papeles son notables, lo que aporta indicios que permiten hipotetizar tanto sobre el parentesco como acerca de la representación de la obra.

En la "Historia del texto", Presotto aborda la tradición textual del libro impreso en 1615. El estudioso aporta aquí también una descripción detallada, para la que tiene en cuenta los once ejemplares cotejados por el equipo de editores, comentando sus rasgos materiales y de contenido y calibrando sus particularidades. Llaman la atención a propósito de este impreso varias cuestiones, como el apresurado proceso de impresión que sufrió y que Presotto desentraña a través del examen de los preliminares y el régimen y carga de trabajo de la imprenta, o el modelo editorial, que no se ajusta exactamente al de comedias adocenadas, que se había extendido algunos años antes. Especial comentario y valoración hace del tipo de errores y variantes —en diferentes estados- que atribuye en su mayoría al copista o al cajista, ilustrándolo con nume- rosos ejemplos.

Por último, hace un repaso crítico de las ediciones modernas, que se inicia con la edición dieciochesca de Nasarre. Comenta y valora el interés y grado de acierto de cada propuesta, bien crítico, ecdótico o divulgativo, y las conecta entre sí, perfilando la historia de recepción crítica de las obras dramáticas cervantinas. Esta tradición críticoecdótica se contempla dentro del conjunto de testimonios que se cotejan en el aparato crítico, como punto de guía y referencia de las enmiendas que introducen los editores de esta colección, si bien no agota las correcciones que estos aplican, algunas muy agudas y nunca antes detectadas. Todas quedan registradas, así como las variantes que presentan los diferentes testimonios, en el aparato crítico. Este, no obstante, no se ofrece de forma completa en este libro, si bien está a disposición de cualquier interesado en la página de la RAE (http://www.rae.es/publicaciones/ obras-academicas/bcrae/comediasy-tragedias-miguel-de-cervantes). Aquí, en cambio, se presenta una versión simplificada, que omite las lecturas de las ediciones modernas, manteniendo solo aquellas que por primera vez sancionan alguna de las enmiendas por las que optan 
los editores. Las lecciones o enmiendas se justifican y explican en la mayoría de casos, con valoraciones de gran interés crítico y (con) textual, con comentarios sobre el tipo de error (por atracción, trivializaciones, confusión en cuanto a la asignación de los parlamentos a sus personajes, entre otros), con consideraciones literarias y lingüísticas y en diálogo con la tradición crítica posterior. Se podría objetar que se hace ardua la navegación por el aparato crítico, que aglutina todas las variantes en un mismo cuerpo textual, especialmente cuando las variantes afectan a más de un verso. No obstante, en la versión extendida del aparato, estas se organizan a principio de línea sistemáticamente, permitiendo una navegación fácil para el interesado en consultar casos concretos.

En lo que respecta a la edición, este equipo realiza una escrupulosa labor crítica sobre los textos, con una lectura rigurosa, teniendo en cuenta el sentido, el idiolecto cervantino, y con especial atención hacia los aspectos métricos y prosódicos. Los criterios de edición apuestan por acercar el texto a los lectores modernos, priorizando la presentación de un texto limpio de llamadas, modernizado en lo modernizable (las grafías, básica- mente, pues se mantienen, incluso, vacilaciones vocálicas para una misma palabra en diferentes momentos) y acentuado y puntuado según las normas vigentes. Cabe una mención a las imposiciones de la Real Academia, pues en alguna ocasión se habría agradecido la tilde diacrítica en los pronombres demostrativos. Se otorga especial atención a los aspectos prosódicos, que se implementan en las notas a pie de página con indicaciones pertinentes para la correcta pronunciación y acentuación de los versos. Se podría hacer un comentario al efecto, que en sentido contrario acaso generara el exceso de fragmentación por puntuación (al separar, por ejemplo, sinalefas). En cualquier caso, sería este un apunte quisquilloso, pues - como aclara la RAE - las normas de puntuación actuales no inciden necesariamente en la prosodia.

Por lo demás, el aparato de notas es exhaustivo y riguroso. Aquí se aporta información de diversa índole, desde aclaración de voces, intertextos y referentes histórico-literarios, hasta comentariosresúmenes y explicaciones de la ironía. Los editores proveen, de esta forma, al lector de claves interpretativas, sutiles en muchos casos, imprescindibles para conectar 
con el texto cervantino. Las "notas complementarias", en el segundo volumen, abundan en datos lingüísticos, literarios, históricos y referenciales, citando fuentes, tanto de la época como modernas, sobre cuestiones sucintamente apuntadas en las notas a pie. Este bloque informativo y documental no solo es fundamental para acercarse a la profundidad y alcance de los textos, sino que constituye una herramienta de enorme interés para familiarizarse con el mundo de Cervantes, en particular, y con el de su siglo, en general.

En los apéndices que siguen, se proporcionan instrumentos para facilitar el análisis y estudio de los textos, así como un desarrollo de cuestiones de recepción, que complementa la revisión crítica de Gómez Canseco y Valle Ojeda en el estudio introductorio. En los dos primeros anejos, más técnicos, los editores resumen los argumentos de cada obra por jornadas, en el primero de ellos, y facilitan el cómputo (y comentario) de los versos para cada comedia, en el segundo. En el tercer anejo, Pinzán y Colombo abundan en datos sobre el impacto y la recepción de la dramaturgia de Cervantes, tanto en el ámbito crítico como en el teatral, poniéndolos en diálogo y contextualizándolos en las corrientes ideológicas literarias vigentes en cada momento. De esta forma, se ofrece una visión cabal de la suerte del teatro cervantino que, en pocas palabras, ha tenido poca incidencia, siendo generalmente malinterpretado e instrumentalizado de acuerdo con particulares intereses ideológicos. Si bien la ola romántica alemana ayudó a la recuperación por el interés de la obra, de la dramática solo se rescataron $\mathrm{La} \mathrm{Nu}$ mancia y los entremeses. Solo en el siglo XX ha recibido más atención, especialmente tras la revisión crítica de Canavaggio en los Setenta. No obstante, parece que solo en contextos conmemorativos, o con fines experimentales, tiene sentido volver a las comedias cervantinas, a juzgar por la trayectoria de las representaciones en las últimas décadas. En el cuarto apéndice, que complementa el estudio de Presotto, Vaccari examina de cerca los papeles de actor que integran la tradición manuscrita de las piezas conservadas, junto con el texto de estos. Finalmente, una extensa bibliografía y un índice de notas cierran este volumen.

En suma, es de indudable valor el trabajo que encierran los dos volúmenes de Comedias y tragedias. Los editores, en perfecta coordina- 
ción, revisan de forma exhaustiva tanto la tradición crítica y ecdótica como las fuentes, para presentar un texto crítico de las obras sumamente riguroso. Los estudios complementarios contextualizan las obras en coordenadas relevantes no solo para entender del texto, sino también para la comprensión cabal de la trayectoria literaria de Cervantes.

Roser López Cruz King's College London 